\title{
Are leptin responses influenced by bright light treatment in healthy young individuals
}

\author{
M. AlBreiki, B. Middleton and S. Hampton \\ Department of Biochemistry \& Physiology, School of Bioscience \& Medicine, Faculty of Health \& Medical Science, \\ University of Surrey, Guildford, GU2 $7 X H$, UK
}

Appetite is controlled by a complex mechanism of hormones, neurotransmitter and neuropeptides both centrally or peripherally within the body. Light has been associated with a reduction in leptin ${ }^{1}$ and an increase in ghrelin ${ }^{2}$, both hormones associated with appetite. Leptin was reported to inhibit hunger and stimulate satiety by acting on receptors in the lateral and medial hypothalamus ${ }^{3}$. Previously, we reported a significant increase in subjective hunger and desire to eat during bright light compared to dim light. The aim of this study was to investigate the effects of light on the appetite hormone, leptin prior to and after a set meal in healthy subjects.

A favourable ethical opinion was obtained from the University Ethics Committee. Seventeen healthy participants, 8 females (22.2 years (SD 2.59) and BMI 23.62 kg/m² (SD 2.3)) 9 males (22.8 years (SD 3.5) BMI $23.8 \mathrm{~kg} / \mathrm{m}^{2}$ (SD 2.06)) were randomised to a two way cross over design protocol; dim light condition ( $<5$ lux) and bright light condition ( $>5001 \mathrm{ux})$, separated by at least seven days. Each session started at 18:00 $\mathrm{h}$ and finished at 06:00 $\mathrm{h}$ the next day. Participants consumed an isocaloric and non-caffeinated evening meal (1066 Kcal, $38 \mathrm{~g}$ protein, $104 \mathrm{~g} \mathrm{CHO}, 54 \mathrm{~g}$ fat, and $7 \mathrm{~g}$ fibre). The meal time were individualised based on melatonin onset (Dim light onset (DLMO)) obtained from participants' $48 \mathrm{~h}$ sequential urine collection. In order to assess subjective appetite, electronic visual analogue scales (VAS) was used (PRO-Diary). Pre-prandial and postprandial plasma samples were collected at specific time intervals to assess leptin. Leptin was measured using a radimmunoassay kit (EMD Millipore). Statistical analysis was carried out using Statsoft STATISTICA with three factor repeated measures ANOVA (gender, time, treatment).
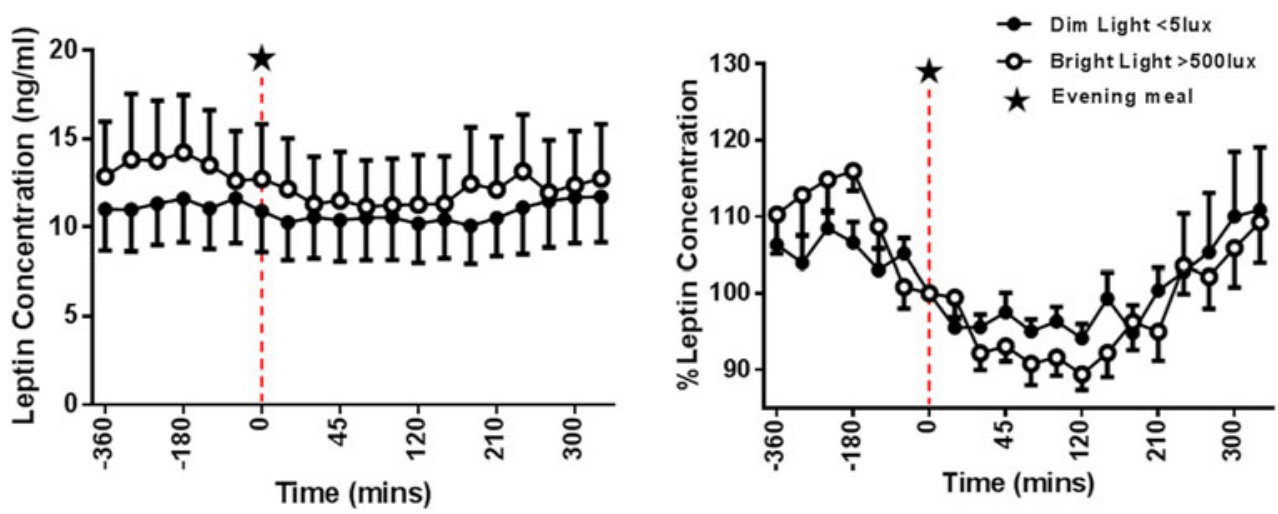

Leptin raw data showed a trend toward a significant increase in plasma leptin under bright light compared to dim light $(\mathrm{p}=0 \cdot 08)$. Females showed a significant greater leptin baseline level than males $[20.13 \pm 3.57 \mathrm{~F}$ and $4.6 \pm 1.04 \mathrm{M}(\mathrm{Mean} \pm \mathrm{SEM})](\mathrm{p}=0.0006)$. The raw data were corrected for basal levels directly prior to the meal (time $=0)$, and plotted as $\%$ basal leptin concentration $($ time $=0$ ). There were no significant differences between the two light conditions on corrected data $(\mathrm{p}=0.57)$.

The raw leptin results are difficult to interpret as lower leptin levels in dim light compared to bright light contradicts the satiation results. \% basal leptin concentration resulted in raised levels in dim light condition that could contribute to the significant increase in hunger and desire to eat in bright light compared to dim light. The significant difference between gender agreed with many studies reporting that females show higher leptin levels than males ${ }^{4,5}$. The changes in leptin concentration may possibly be influenced by insulin levels. Further hormone analysis is required to explain these results.

1. Kalsbeek A, Fliers E, Romijin JA et al. (2001) Endocinology 142, 2677-2685.

2. Yildiz BO, Suchard MA, Wong ML et al. (2004) National Academy of Science 101, 10434-10439.

3. Elmquist J, Elias C, Saper C. (1999). Neuron 22, 221-232.

4. Kennedy A, Gettys TW, Watson P et al. (1997) J Clin Endo \& Metab 82, 1293-1300.

5. Hickey MS, Israel RG, Gardiner SN et al. (1996) Biochemical \& Molecular Medicine 59, 1-9. 